\title{
Congenital portosystemic shunt
}

INSERM

\section{Source}

INSERM. (1999). Orphanet: an online rare disease and orphan drug data base. Congenital portosystemic shunt. ORPHA:480531

Congenital portosystemic shunt is a rare, congenital anomaly of the great veins characterized by an abnormal communication between one or more veins of the portal and the caval systems, resulting in complete or partial diversion of the portal blood away from the liver to the systemic circulation. Clinical manifestations include liver atrophy, hypergalactosemia without uridine diphosphate enzyme deficiency, hyperammonemia, encephalopathy (resulting in learning disabilities, extreme fatigability and seizures), pulmonary hypertension, hypoxemia from hepatopulmonary syndrome and benign or malignant tumours. 